\title{
Os framings da violência sexual infanto-juvenil em webnotícias: estudo de caso no G1 e Folha.com
}

\author{
Giovandro Marcus Ferreira \\ Dayanne Pereira da Silva
}

Resumo: $\mathrm{O}$ artigo tem como objetivo fazer uma análise pelo viés de framings para verificar como ocorre a cobertura noticiosa da violência sexual infanto-juvenil no G1 e Folha.com, no período de 2009 a 2011. A pesquisa tem como hipótese inicial que as notícias factuais sobre o tema não apresentam uma contextualização necessária para a compreensão do fenômeno violência sexual infanto-juvenil enquanto acontecimento noticioso. As webnotícias são analisadas de forma quantitativa e qualitativa e segmentadas nos tipos de framing (de conflito, responsabilidade, interesse humano, consequências econômicas e moralidade) propostos por Semetko e Valkenburg (2000). Os resultados revelam que a temática é recorrente nos sites analisados através do viés factual; no entanto, o viés do acontecimento noticioso preventivo, conceitual e estatístico é ainda pouco explorado.

Palavras-Chave: framing; agenda-setting; violência sexual infanto-juvenil; Folha.com; G1.

Abstract: The framings of juvenile sexual violence in webnews: a case study of G1 and Folha.com

- This paper aims to examine, through framing bias, the news coverage of sexual violence against children and adolescents in G1 and Folha.com, in the period of 2009 to 2011. The research assumes the initial hypothesis that the factual news on the theme does not present a necessary contextualization for the understanding of the phenomenon of sexual violence against children and adolescents, as event news. The webnews are quantitatively and qualitatively analyzed and segmented in types of framing (conflict, responsibility, human interest, economic consequences and ethics) proposed by Semetko and Valkenburg (2000). The results show that the theme is recurrent in sites analyzed through factual bias, but the preventive, conceptual, statistical bias of the news event is still little explored.

Keywords: framing; agenda-setting; juvenile sexual violence; Folha.com; G1. 


\section{Introdução}

Em 2006 a Agência de Notícias dos Direitos da Infância (ANDI) realizou uma pesquisa na mídia impressa sobre os temas mais abordados em relação a "eleições e infância". O tema saúde, que engloba violência em geral, abuso, exploração sexual e trabalho infantil, esteve praticamente ausente do debate. A cobertura da temática não chegou a 2\% em 2006 (ANDI 2006).

Os veículos de comunicação não privilegiam em geral a temática da violência sexual infanto-juvenil em suas pautas. Dados de uma pesquisa da ANDI e da Rede ANDI América Latina sobre a cobertura jornalística de 12 países, de 2005 a 2007, na qual foram analisados 795 mil textos sobre a temática de direitos e qualidade de vida de crianças e adolescentes, revelaram um quadro preocupante no que refere à divulgação de indicadores que qualificam a cobertura das notícias com referência a políticas públicas (ANDI, 2009).

Esse artigo propõe mensurar de que forma esse assunto é abordado em sites de notícias de grande repercussão como o G1 e Folha.com, através da seleção de notícias por meio de palavras-chave (violência sexual infantil, abuso sexual infantil, violência sexual infanto-juvenil e abuso sexual infanto-juvenil) no período de 2009 a 2011.

A imprensa tem uma função importante no exercício da cidadania através dos meios de comunicação. Os jornalistas podem sugerir e executar pautas que favoreçam a cobertura dos direitos e deveres do cidadão, ou seja, informar sobre temas de interesse público de maneira qualificada. No Título III do Estatuto da Criança e do Adolescente (ECA), que trata da prevenção, no art.70, tem-se a indicação: "é dever de todos prevenir a ocorrência de ameaça ou violação dos direitos da criança e do adolescente" (ECA, 1990, p.42 apud SILVA, 2011).

Nesse contexto a imprensa pode ainda influenciar a agenda pública. Tal influência é contemplada por abordagens como a agenda-setting ou teoria do agendamento. Outra abordagem que perpassa o agendamento é a teoria do framing - ou enquadramento da cobertura - na qual aspectos específicos de uma questão são destacados em detrimento de outros, o que ajuda a construir a interpretação do público (ANDI, 2009, p.11).

Pode-se destacar quatro objetivos que norteiam este artigo: o primeiro é a busca em analisar o framing (enquadramento) da violência sexual infanto-juvenil em duas direções: a) notícias que divulgam casos de violência que aconteceram no Brasil e no mundo (restringindo a publicação do fato noticioso) e b) notícias que abordam a temática por um viés preventivo ou aprofundado com dados (acontecimento noticioso). O segundo objetivo é o de detectar, através dessa análise dos enquadramentos, quem pauta a temática nos veículos estudados, se são os próprios veículos ou, sobretudo, as agências de notícias. O terceiro objetivo é o de segmentar as notícias nos tipos de frames (de conflito, responsabilidade, interesse humano, consequências econômicas e moralidade) propostos por Semetko e Valkenburg (2000). Enfim, o quarto objetivo é o de identificar 
quais assuntos são mais recorrentes, como fruto da escolha da segmentação em framings temáticos (criados a partir da análise prévia do corpus) que divide as notícias nas seguintes categorias: crimes e prisões; denúncia; estatísticas (divulgação de dados nas notícias) e o framing políticas públicas (ações de governo).

A escolha dos sites G1 e Folha.com se justifica porque eles estão em primeiro e segundo lugar, respectivamente, no ranking da pesquisa da ComScore ${ }^{1}$ referente ao consumo de notícias no Brasil em setembro de 2010, o G1 com 11,8 milhões e o Folha.com, com 11 milhões de visitantes únicos.

\section{Violência sexual infanto-juvenil, como abordar o tema?}

A banalidade da violência na imprensa justifica os enquadramentos cômodos e sem aprofundamento em notícias referentes à temática infanto-juvenil. Um dos propósitos deste artigo é investigar, através de uma análise quantitativa e qualitativa, a maneira como a cobertura sobre essa temática tem priorizado o recorte factual dos casos de violência contra crianças e adolescentes, deixando à margem uma abordagem mais conceitual e preventiva sobre o assunto (acontecimento noticioso).

Uma das funções desse estudo é destacar o papel dos webjornalistas e do webjornalismo, no domínio dos direitos da criança e do adolescente, referente ao tratamento editorial qualificado em temas alusivos à prevenção da violência sexual infanto-juvenil.

\section{Perspectiva teórica da agenda-setting e do framing}

A agenda-setting surgiu na década de 70 e, no seu interior, é articulada a visão de que a mídia agenda as questões que serão socialmente discutidas, além da capacidade da mídia de influenciar a posição dos temas no ranking de prioridades. Em artigo seminal, Mc Combs e Shaw (1972) investigam o agendamento dos mass media na campanha presidencial de 1968. O estudo tentou associar os temas-chave da campanha apontados pelos eleitores de Chapel Hill com o conteúdo dos meios de comunicação de massa usados durante a campanha.

De acordo com Dearing e Rogers (1996) o início das pesquisas em agenda setting data de 1922, quando Walter Lippman faz relação entre a agenda dos mass media e a agenda pública; anos depois, de 1948 a 1964, Paul F. Lazarsfeld e Robert K. Merton estudam o status da mídia e a relevância dada a certos tópicos e em 1972, Mc Combs e Donald Shaw nomeiam o processo da agenda setting investigando o método de determinação da agenda pública para uma hierarquia de assuntos.

1 Resultado da pesquisa disponível em: <http://www.comscoredatamine.com/2010/11/most-visited-newswebsites-in-brazil/>. 
No âmbito da psicologia cognitiva, o antropólogo Gregory Bateson fez referência em 1955 aos processos de recepção das mensagens; o conceito de frame definiu nesse contexto o "marco" (referencial) da interpretação, no qual alguns indivíduos detêm mais atenção a determinados assuntos, em detrimento de outros. Para Bateson esses "marcos" ou "quadros" são instrumentos da psique que aprofundam as diferenças de percepção das coisas (SÁDABA, 2007, p. 31).

Erving Goffman em seu livro seminal para os estudos de framing, Frame Analysis: an essay on the organization of experience, resgata o conceito de "marco" da psicologia de Bateson e o aplica na sociologia, expandindo o conceito para explicar como os acontecimentos estão organizados em nossa mente e na sociedade. Na perspectiva de Goffman, o framing é definido como quadros que são acionados pelas pessoas para definir situações e dar sentido aos acontecimentos. No entanto, Goffman apresenta o framing na perspectiva da recepção dos conteúdos, o que pode ser chamado de "framing da audiência". Este artigo apresenta a perspectiva do framing da mídia definidos por Semetko e Valkenburg (2000)

Muito já se falou sobre o framing ser uma variação da agenda setting, mais especificamente o segundo nível de agenda setting ou agenda de atributos. Reese (2007) chama essa relação de irônica, pois na concepção do autor o framing é uma reação contra as limitações teóricas da agenda setting. Enquanto Entman (1993) define o enquadramento como a seleção de alguns aspectos da realidade percebida mais salientados em um texto de comunicação, de tal forma a promover a definição de um problema, a interpretação causal, a avaliação moral e/ou a recomendação de tratamento para o item descrito.

Entman (1993) também destaca que os frames tem quatro componentes no processo de comunicação: o comunicador que consciente ou inconscientemente decide o que dizer, guiado por frames que organizam seu sistema de crenças; o texto que contém frames que se manifestam com a presença ou ausência de palavras-chaves, frases, imagens esteriotipadas, fontes de informação que reforçam fatos ou julgamentos; os frames que guiam o pensamento do receptor e podem não corresponder à intenção do frame do comunicador; e a cultura que é o estoque de frames geralmente invocados por constituirem os frames comuns expostos no discurso e no pensamento da maioria das pessoas em um agrupamento social.

Semetko e Valkenburg (2000) compilaram os cinco frames mais recorrentes de notícias identificados em estudos anteriores sobre a elaboração e efeitos de enquadramento: atribuição de conflitos, responsabilidade, interesse humano, consequências econômicas e moralidade. Esses foram os tipos de frames utilizados durante nossa pesquisa.

É importante explicar como deve ser identificado cada tipo de frame nas notícias analisadas neste artigo. De acordo com Semetko e Valkenburg (2000) o frame de conflito enfatiza a relação conflituosa entre indivíduos ou instituições; o frame de interesse humano foca na personalização da notícia com a intenção de emocionar o público; o frame 
de consequências econômicas destaca as implicações econômicas em um indivíduo, grupo, instituição, região ou país; o frame da moralidade envolve questões que contextualizam a temática religiosa ou moral e o frame da responsabilidade atribui a culpabilidade de uma causa ou solução de uma questão ou problema ao governo, indivíduo ou grupo.

\section{Fato e acontecimento}

Nesse tópico buscar-se-á apresentar alguns conceitos e noções sobre fato e acontecimento, compreendendo o primeiro como o "mundo a comentar" ${ }^{2}$, no sentido genuíno e em estado bruto, tal como se apresenta, e o segundo como o "mundo comentado", submerso no que Charaudeau (2010, p. 94) chama de "universo de discurso". Charaudeau (2010, p. 95) afirma ainda que o acontecimento nunca é transmitido à instância de recepção em seu estado bruto; para sua significação, depende do olhar do sujeito que o integra em um sistema de pensamento fazendo-o inteligível.

Para Wolf (2003, p. 85), os valores-notícia estão inseridos em todo o processo de produção da notícia, favorecendo a rotinização do trabalho jornalístico, e funcionam de duas maneiras na seleção dos acontecimentos que serão transformados em notícia. Na primeira funcionam como critério de seleção para inclusão no produto final e, na segunda, como "linhas-guia" do que deve ser realçado, do que deve ser omitido e do que deve ser prioritário durante a preparação da notícia na apresentação do material.

Os valores-notícia de seleção funcionam como uma espécie de tipificação ou classificação não abstrata, coerente e organizada, que tem como objetivo a escolha de material noticioso. Subdivide-se em critérios substantivos (conteúdo) que articulam a importância, o interesse da notícia e os critérios contextuais que consistem no processo de produção, na imagem que os jornalistas têm do público e na concorrência no mercado informativo (WOLF, 2003, p. 86-88).

Em uma reflexão sobre verdade e perspectiva no jornalismo, Gomes (2009) apresenta questões que ajudam a pensar o conceito de fato. Para o autor "os fatos devem poder reger os parâmetros de sua própria interpretação. Eles são algo dado e induzem a sua própria apreensão e representação". Essa percepção dos fatos que é o papel do jornalista, quando utiliza as fontes e constrói o processo de hierarquização, se aproxima da perspectiva de Rodrigues (1993), que discute acontecimento como efeito de realidade e define-o como tudo aquilo que irrompe na superfície da história entre uma multiplicidade aleatória de "fatos virtuais". Para o autor, o que torna um fato em acontecimento é a previsibilidade: "quanto menos previsível for, mais probabilidade tem de se tornar notícia e de integrar assim o discurso jornalístico"(RODRIGUES, 1993, p. 27).

2 O "mundo a comentar" nunca é transmitido tal e qual à instância de recepção. Ele passa pelo trabalho de construção de sentido de um sujeito de enunciação que o constitui em um "mundo comentado" [...]. O acontecimento se encontra nesse "mundo a comentar" como surgimento de uma fenomenalidade que se impõe ao sujeito, em estado bruto, antes de sua captura perceptiva e interpretativa (CHARAUDEAU, 2010, p.95). 
A notícia é constituída de elementos discursivos organizados hierarquicamente por um sujeito (jornalista) que está imerso no mundo da enunciação (individual e coletiva); nesse contexto, pode-se associar o conceito de Foucault (2010, p. 139) de "domínio enunciativo" que não parte do lugar possível dos sujeitos que falam. Não importa quem fala, mas o que diz não é dito de qualquer lugar, por isso a relevância empregada no conteúdo que o jornalista publica e no veículo onde publica.

\section{Problemática e procedimentos metodológicos}

Há aqui uma hipótese e dois questionamentos que norteiam a análise do corpus noticioso desta pesquisa. Tal investigação tem como hipótese inicial que as notícias factuais sobre o tema não apresentam uma contextualização necessária para a compreensão do fenômeno da violência sexual infanto-juvenil enquanto acontecimento noticioso. Buscando vertebrar tal afirmação inicial, levanta-se duas questões: (1) quais são os tipos de frames (conflito, interesse humano, moralidade, consequências econômicas ou responsabilidade) mais recorrentes na cobertura do Folha.com e G1 referentes à violência sexual de crianças e adolescentes? (2) que tipos de framings temáticos (criados a partir da análise prévia do corpus) que dividiram as notícias em: crimes e prisões; denúncia; estatísticas (divulgação de dados nas notícias) e políticas públicas (ações de governo) são mais recorrentes?

A coleta de notícias nos sites foi realizada através dos campos de pesquisa, com a procura das palavras-chave - violência sexual infantil, abuso sexual infantil, violência sexual infanto-juvenil e abuso sexual infanto-juvenil. Foi realizada também a seleção do filtro do calendário delimitando o período de janeiro de 2009 a agosto de 2011. Foram selecionadas 10 notícias em cada ano (2009, 2010 e 2011) nos dois veículos, totalizando 60 notícias, 30 de cada veículo. Inicialmente foi realizada a leitura flutuante ${ }^{3}$ do material para identificar se todos eles podiam fazer parte do corpus dessa pesquisa, ou seja, os que integravam a temática da violência sexual infanto-juvenil. O critério de recorte da análise de conteúdo foi o que Bardin (2010, p. 131) chama de análise temática ${ }^{4}$.

Durante a análise dos enquadramentos foi possível identificar quem pauta essa temática nos veículos estudados, se são os próprios veículos ou as agências de notícias, verificando no topo da notícia, embaixo do título, quem "assinava" a notícia. Logo depois foi realizada uma leitura crítica qualitativa das notícias e foram segmentadas por tipos de frames propostos por Semetko e Valkenburg (2000).

O critério de recorte utilizado é o que Bardin (2010, p. 131) chama de Análise Temática, que consiste em descobrir os "núcleos de sentido" que compõem a comunicação e cuja presença ou frequência de aparição pode significar alguma coisa para o objetivo

3 É uma primeira leitura intuitiva, muito aberta a todas as ideias, reflexões, hipóteses, numa espécie de brainstorming individual (BARDIN, 2010, p. 71).

4 Fazer uma análise temática consiste em descobrir os "núcleos de sentido" que compõem a comunicação e cuja presença ou frequência de aparição podem significar alguma coisa para o objeto analítico (BARDIN, 2010, p.131). 
analítico escolhido. No caso desse artigo foram utilizados dois recortes, de notícias factuais e notícias em que o viés do acontecimento noticioso e de caráter preventivo fica mais evidente, e ainda foram criados alguns framings temáticos que formam esses núcleos de sentido.

Inspirada na metodologia utilizada por Semetko e Valkenburg (2000), esta pesquisa também categorizou as notícias nos frames de conflito; interesse humano; responsabilidade; moralidade e econômico. Consideramos os framings como recortes da realidade e não como caixas estanques para engessar o conteúdo analisado.

Após essa seleção por tipos de framing, as notícias foram separadas por framings temáticos, criados a partir da incidência dos temas no corpus analisado: crimes e prisões, denúncia (que envolvia denúncia sobre o tema); estatísticas (divulgação de dados ou relatórios relacionados à violência sexual infanto-juvenil) e políticas públicas/ações do governo (notícias sobre ações do governo com relação à temática).

\section{Analisando os dados: a prioridade da cobertura}

A webnotícia já tem um caráter factual por natureza, ou seja, entra em pauta o que está acontecendo no momento, entretanto, nessa etapa da análise tentamos identificar quais notícias estavam restritas apenas ao fato, sem aprofundar o tema com questões legais, fontes especializadas, box informativos com dados estatísticos, entre outros. Foi diagnosticado que no Folha.com houve um aumento gradativo de $10 \%$ por ano nas notícias com acontecimento noticioso, no entanto, a quantidade não superou a de notícias factuais, que representaram 90\% em 2009, 80\% em 2010 e 70\% em 2011. No G1, o cenário não foi diferente: em 2009 foram 90\% de notícias factuais, em 2010, 80\% e em 2011,90\%. Portanto, a hipótese acerca da factualidade da cobertura dos dois veículos de informação foi contemplada na perspectiva levantada no início do trabalho.

Sobre a origem das pautas da cobertura do Folha.com e do G1, foi investigado se eram originadas dos veículos ou seguimento de pautas de agências de notícias. Foi diagnosticado que na Folha.com nos três anos analisados foram encontradas 10 notícias (33\% do total) com abordagem preventiva, das quais 5 eram de agências de notícias (2 internacionais e 3 nacionais). Existe, portanto, uma tendência do veículo em ser agendado pelas agências.

No G1 também foram encontradas 10 notícias com temática preventiva, das quais 8 eram do G1, mas em parceria com as afiliadas, enquanto 2 foram originadas de agência de notícias. No caso do G1 tem-se uma vantagem maior, por se tratar de um veículo com várias afiliadas em todo o Brasil e por isso percebe-se uma tendência de divulgar notícias em parceria com os veículos do próprio grupo. No caso do Folha.com as agências fonte foram: France Press, BBC Brasil e Afeganistão, Associated Press e Agência Brasil. Por causa dessa diversidade de enfoques foi detectado que o G1 prioriza a cobertura da violência sexual infanto-juvenil no Brasil, enquanto no Folha.com essa cobertura é ampliada para o mundo, dessa forma expõe a cobertura do tema de outros países. 
Os temas preventivos considerados são aqueles que colaboram para a perpetuação de práticas ou informações relevantes, com conhecimento preventivo sobre a modalidade de violência estudada. No Folha.com percebe-se maior diversidade na abordagem, que aumentou de 20\% em 2009 para 40\% em 2010 e manteve-se estável até agosto de 2011.

No G1 não houve diversidade de enfoques nesse aspecto: $60 \%$ das notícias citavam prevenção e/ou aprofundaram o tema em 2009, 50\% em 2010 e 30\% em 2011. Percebese então uma redução gradativa do G1 em abordar a temática por um viés de informação preventiva, com redução brusca de 20\% das notícias de 2010 para 2011.

Nem toda notícia factual era aprofundada, mas toda notícia com algum aprofundamento citando ECA, leis, dados estatísticos ou alguma informação complementar, era factual no Folha.com e no G1 por se tratar de veículos online e com atualização constante. Essa categorização foi realizada apenas para diferenciar as notícias que apresentavam somente o factual das notícias que traziam informações relevantes e ampliadas sobre o contexto da situação (acontecimento noticioso).

\section{Enquadramentos temáticos das notícias no Folha.com e G1}

Após análise foi possível perceber como a cobertura da violência sexual infantojuvenil surge nos framings temáticos: crimes e prisões; denúncia; estatísticas e políticas públicas/ações de governo. Os índices, abaixo, representam a quantidade de notícias segmentadas em cada temática nos veículos estudados. Nota-se uma prevalência por notícias que abordam crimes e prisões, com 18 notícias no Folha.com e 22 no G1. O segundo enquadramento mais abordado foi o de denúncia, com 16 notícias no Folha. com e também 16 no G1.

De forma geral foi diagnosticado que o enquadramento predominante em ambos os veículos foi o de Crimes e Prisões, com enfoque em casos de crimes, prisões, andamento de casos e julgamentos entre outros aspectos associados a esse framing.

- Enquadramento 1 - Crimes e prisões - Com relação a esse framing o G1 apresentou 22 notícias das 30 analisadas, ou seja, 73\% das notícias não ampliaram a discussão da temática, apenas noticiaram os fatos como crimes sexuais, andamento de investigações, processos, resultados de julgamentos, entre outros. No Folha.com 18 notícias das 30 analisadas estão enquadradas nesse framing. Em tal framing, o Folha.com contextualizou melhor os fatos publicados, enquanto o G1 abordou o fato somente, sem citar dados, fontes importantes e pautas com direcionamento além do factual.

- Enquadramento 2 - Denúncia - No framing temático 'denúncia' houve 16 notícias (53\%) no Folha.com. Há notícias que relatam de forma dispersa como e 
quem realizou as denúncias sobre os casos de violência, cita números referentes a denúncias e criação de plataformas online, além do pedido da presidente da Suíça para a criação de um registro nacional com o nome de padres acusados de abuso sexual. No G1 houve 16 notícias também segmentadas como denúncia (da vítima, disque 100, dos pais, parentes, pessoas que não eram da família e relatório sobre o caso). Com base nesses resultados é possível perceber que $53 \%$ das notícias de ambos os veículos seguem a vertente da denúncia, em alguns momentos como foco principal, em outros como elemento coadjuvante.

- Enquadramento 3 - Estatística - Nesse framing foram localizadas 10 notícias no Folha.com e 09 notícias no G1. Esse framing traz informações sobre pesquisa e dados referentes à temática. No Folha.com surgem temas como um levantamento de dados da Polícia Rodoviária Federal de pontos de risco de exploração sexual de crianças e adolescentes no país, uma pesquisa da Secretaria Especial dos Direitos Humanos que aponta as meninas como maioria de vítimas de violência sexual. Entre as 9 notícias do G1 que contextualizam as estatísticas, a maioria (4) traziam dados do disque 100, 2 abordaram a CPI da pedofilia e dados da ONG Safernet, 1 trouxe informações do Ministério Público, 1 apresentou dados de relatório específico sobre pai que abusava das filhas no Reino Unido e 1 citou dados de um relatório da Comissão de Assuntos Internos da União Européia. No enquadramento Estatística, o Folha.com apresentou melhor explanação da temática, tanto em quantidade que demonstra uma disponibilidade maior de espaço para o tema, mas também pela qualidade das abordagens dos dados e relatórios.

- Enquadramento 4 - Políticas Públicas/Ações de governo - O Folha.com e o G1 apresentaram 7 notícias cada nesse enquadramento; no entanto, cada veículo direcionou suas pautas de uma maneira particular. No Folha.com a lei que estabelece punições mais rigorosas contra a pornografia infantil e crimes de abuso sexual envolvendo crianças e adolescentes na internet, sancionada pelo presidente Lula em 2008, aparece em 2 notícias, com textos semelhantes, e a CPI da pedofilia aparece apenas 1 vez. A CPI da pedofilia foi criada em 2008, pelo então senador Magno Malta (PR-ES) e apresentou relatório final em 2010, mas na amostra aleatória coletada o Folha.com não contemplou o assunto. No G1, a CPI da pedofilia aparece em 4 notícias, que apresentam as ações e resultados como o "depoimento único" para vítimas de abuso, as prisões da operação Turko (anagrama da palavra Orkut) da Polícia Federal, a aprovação do projeto que altera o prazo de prescrição de crimes de pedofilia. As outras 3 notícias que entraram nesse enquadramento abordaram: exploração sexual infantil; o projeto "Policial Amigo", que tem ações voltadas para crianças e adolescentes vítimas de abuso e lançamento de uma campanha preventiva. Na amostra estudada 
o Folha.com apresentou maior diversidade de enfoques e abrangência de temas, enquanto no G1 o foco ficou na CPI da Pedofilia, que foi um assunto importante, mas precisava ser contextualizado com temáticas relacionadas.

\section{Enquadramentos (segundo Semetko e Valkenburg) das notícias no Folha.com e G1}

Para responder ao primeiro questionamento dessa pesquisa (quais são os tipos de frames mais recorrentes na cobertura do Folha.com e G1 sobre violência sexual de crianças e adolescentes?), foi preciso categorizar as notícias com os framings propostos por Semetko e Valkenburg (2000), e com a análise desses enquadramentos foi identificada maior recorrência dos frames responsabilidade, moral e interesse humano nos referidos veículos.

Uma das razões possíveis desse resultado é a característica da temática - a violência sexual infanto-juvenil - que geralmente elenca assuntos que envolvem o caráter moral, como por exemplo, em notícias que abordam a questão de violência sexual infantojuvenil, em casos de aborto após estupro e risco de morte para a mãe, e nesse mesmo enquadramento entra a questão da opinião contrária da igreja sobre o assunto, que nesse estudo ficou segmentado como framing de conflito, mas que também envolve valores morais, coexistindo assim com o framing de moralidade.

Nos framings (responsabilidade, moral e interesse humano) mais recorrentes em ambos os veículos, é notória a abordagem de relatos de como as pessoas e grupos podem ser afetados pela questão da violência sexual infanto-juvenil; a culpabilidade do fato sempre é direcionada para alguém, na maioria dos casos, para o agressor e em alguns casos para o governo; surgem também níveis de moralidade nas notícias, como a questão religiosa, aborto, pais que deveriam proteger e abusam dos filhos, entre outras questões.

No Folha.com 9 notícias apresentaram o framing conflito, ou seja, enfrentamento entre pessoas e grupos, como entre os abusadores ou exploradores sexuais e policiais. No entanto, a forma de conflito mais ressaltada no Folha.com foi a da relação entre religiosos e a violência sexual infanto-juvenil. Os conflitos existentes eram entre as vítimas e os abusadores, as vítimas e a igreja, enfocando casos de violência. Em todas essas notícias coexistem os framings de responsabilidade, interesse humano e moralidade. A responsabilidade ficou caracterizada sempre como dirigida a algum agressor, suspeito ou ao Papa que foi responsabilizado por proteger ou não denunciar clérigos que cometeram abuso sexual infantil, de acordo com as notícias.

No G1 foram apenas 3 notícias de conflito, uma delas sobre a operação Turko, já mencionada. A outras duas referiram-se a atividades ligadas a religiosos (igreja) e a médicos (ciência) que entram em choque, acerca de notícia que expõe caso de aborto após estupro.

O framing de consequências econômicas, que é caracterizado por menção de perdas ou ganhos financeiros, ficou representado no Folha.com por notícias que abordavam 
investimentos em ações sobre a temática da violência sexual infanto-juvenil e relatos de crianças exploradas sexualmente no Afeganistão. No G1 apenas uma notícia ficou enquadrada nesse item, com a seguinte manchete - "Disque-Denúncia oferece R\$ 1 mil por informação de menina morta no Aterro" - a oferta de recompensa pela denúncia configura um ganho com a questão.

\section{Considerações Finais}

Este estudo teve como objetivo analisar a cobertura sobre a violência sexual infantojuvenil no G1 e Folha.com no período de 2009 a 2011. Com base na amostra constituída através de palavras-chave, foi possível fazer um estudo panorâmico com relação à abordagem da temática acerca dos tipos de frames, a origem da pauta e a oscilação, no período analisado, do acontecimento noticioso.

O enquadramento das abordagens dessa temática tende a seguir a cobertura factual e não a cobertura preventiva e mais aprofundada (acontecimento noticioso), como foi possível analisar a partir das formas como os dois veículos trabalham os temas e constróem suas notícias. Como resultado foi detectado que, em ambos veículos, existe a prevalência do viés factual, contemplando uma perspectiva apontada inicialmente nesse estudo. Existe uma tendência dominante em divulgar apenas o factual sobre a temática, sem um aprofundamento do assunto, não fugindo de uma tendência marcada pela brevidade, concisão e, também, superficialidade.

Outra constatação do estudo comparativo coloca em relevo a origem das pautas preventivas ou que aportavam alguma informação nesse sentido. Do total de notícias analisadas no Folha.com apenas 10 apresentaram esse aspecto e desse total, 5 eram oriundas de agências de notícias (France Press, BBC Brasil e Afeganistão, Associated Press e Agência Brasil). No caso do G1, foram 10 notícias e 8 foram originadas do próprio veículo, levando-nos a concluir, então, que o G1 nesse aspecto prioriza mais a cobertura preventiva e apresenta maior diversidade de enfoques do que o Folha.com. No entanto, é preciso ressaltar que, nos dois sites, o total de notícias analisadas ocupa um pequeno espaço da cobertura sobre a temática estudada: no site Folha.com representando 17\% e no site G1 equivalendo a $27 \%$.

Quando as notícias foram separadas por framings temáticos, foi possível revelar que os assuntos que envolvem a temática da violência sexual infanto-juvenil são recorrentes nos sites analisados, através da perspectiva factual, sendo o viés preventivo, conceitual e estatístico ainda pouco explorado. Nesse aspecto, o Folha.com foi mais diverso e abrangente, pois conseguiu relacionar a questão da violência sexual infantil com a questão moral, do aborto, de clérigos e pais que abusam, entre outros temas, colocando o assunto em uma perspectiva que promove a reflexão. 
Foi percebido também, durante a análise das notícias, que o fluxo sobre a temática da violência sexual infanto-juvenil aumenta no mês de maio, pois o dia 18 é o Dia Nacional de Combate ao Abuso e exploração Sexual de Crianças e Adolescentes, data sancionada em 2000. O projeto de criação dessa data foi de autoria da então deputada e presidente da Frente Parlamentar pela Criança e Adolescente do Congresso Nacional, Rita Camata (PMDB-ES). A data foi criada em homenagem a uma menina capixaba que foi sequestrada, espancada, estuprada e assassinada, mas o crime ficou impune (Caso Araceli). Das 60 notícias analisadas, 7 da Folha.com e 5 no G1 foram publicadas no mês de maio, o que representa $20 \%$ do total.

Esse estudo representa parte de uma pesquisa que pretende analisar um maior número de notícias para ter uma amostra mais representativa dos períodos investigados. No entanto, os resultados aqui apresentados podem contribuir para esta e outras pesquisas sobre enquadramentos da mídia no que tange à abordagem da violência sexual contra meninos e meninas em seus diversos recortes. Tal tema tem tido uma ressonância na academia, evidenciando, de um lado, maior sensibilidade da sociedade em relação à violência contra a infância e, de outro, a importância dos meios de comunicação em uma sociedade cada vez mais mediatizada. Se o provérbio africano afirma que "é preciso todo um vilarejo para educar uma criança", na sociedade contemporânea, os meios de comunicação têm uma importância destacada na humanização do mundo infantil e adolescente nesta "aldeia ou vilarejo global".

Giovandro Marcus Ferreira é professor da Faculdade de Comunicação da UFBA; coordena o Centro de Estudo e Pesquisa em Análise do Discurso e Midia (CEPAD) e o Centro de Estudo em Comunicação, Democracia e Cidadania (CCDC). Fez o doutorado e mestrado em Ciências da Informação Medias, no Institut Français de Presse et Communication (Université Paris 2 Panthéon-Assas). É pesquisador do $\mathrm{CNPq}$.

giovandro.ferreira@gmail.com

Dayanne Pereira da Silva é jornalista e mestre pela UFBA. É pesquisadora no CEPAD.

dayannepsm@gmail.com 


\section{Referências}

ANDI. Direitos, infância e agenda pública 2005-2007: uma análise comparativa da cobertura jornalística latino - americana. Brasília: ANDI; Rede ANDI América Latina, 2009.

A agenda da infância nas eleições de 2006. Brasília: Andi; Unicef, 2006.

Guia de referência para o diálogo com a mídia: enfrentamento à exploração sexual de crianças e adolescentes. Brasília: ANDI, 2008.

Exploração Sexual de Crianças e Adolescentes - guia de referência para a cobertura jornalística. Disponível em: < http://violenciasexual.andi.org.br/>. Acesso em: 9 mai. 2010.

BRASIL. Estatuto da Criança e do Adolescente: Lei 8.069/90, de 13 de Julho de 1990. Brasília: Senado Federal; 1990.

BRITES, M. J. Fontes e seus enquadramentos: as notícias sobre delinquência juvenil. Biblioteca online de ciência da comunicação. 2010.

CARLSSON, U; FEILITZEN, C. (Orgs.). A criança e a mídia: imagem, educação, participação. 2. ed. São Paulo: Cortez; Brasília: UNESCO, 2002.

ChARAUDEAU, P. O Discurso das Mídias. São Paulo: Contexto, 2010.

DEARING, J. W.; ROGERS, E. M. (1996), Comunication Concepts 6: Agenda-Setting. Thousand Oaks, Sage.

ENTMAN, R. M. Framing: Toward clarification of a fractured paradigm. Journal of Communication. V. 43 , n. 4,1993 . p. $51-58$

FOUCAULT, M. Arqueologia do Saber. RJ: Forense, 2010.

GOMES, W. Verdade e Perspectiva: a questão da verdade e o fato jornalístico. In: GOMES, W. Jornalismo, fatos e interesses. Vol. 1, Florianópolis : Insular, 2009, p.27-66.

GOFFMAN, E. Frame analysis: an essay on the organization of experience. Boston: Northeastern University Press, 1974.

GONÇAlves, H. S; BRANDÃO, E. P. (Orgs.). Psicologia Jurídica no Brasil. Coleção Ensino da Psicologia. Rio de Janeiro: NAU Editora, 2004.

REESE, S. D. The framing project: a bridging model for media research revisited.In: Journal of Communication. V. 57, p. 148-154, 2007.

RODRIGUES, A. D. O Acontecimento. In: TRAQUINA, Nelson (org.). Jornalismo: questões, teorias e "estórias". Lisboa: Veja, p. 27-33, 1993.

SÁDABA, T. Framing: el encuadre de las noticias. El binomio terrorismo-medios. La crujía, Buenos Aires, 2008, p.252.

SILVA, D. P. Cibernautas em Ação: estudo da interatividade em notícias relacionadas à violência sexual Contra Crianças e Adolescentes no A Tarde On Line, p. 101, 2011. Disponível em: < http:// www.insite.pro.br/2011/Novembro/cibernautas_criancas_atardeonline.pdf>.

SEMETKO, H. A.; VALKENBURG, P. M. Framing european politics: a content analysis of press and television news. Journal of Communication, v. 50, p. 93-109, 2000.

WOLF, M. Teorias da Comunicação. $8^{a}$ Edição. Editora Presença. Lisboa, Portugal, 2003. 